\title{
Effects of HCN Channels in the Rostral Ventrolateral Medulla Contribute to the Cardiovascular Effects of Propofol
}

\author{
Zhiqiang Hu, Zhilin Wu, Jie Gao, Qi Jia, Na Li, Yeling Ouyang, Shanglong Yao, \\ and Xiangdong Chen
}

Department of Anesthesiology, Institute of Anesthesiology and Critical Care Medicine, Union Hospital of Tongji Medical College,
Huazhong University of Science and Technology, Wuhan, Hubei, People's Republic of China

Received January 29, 2018; accepted August 30, 2018

\section{ABSTRACT}

Hyperpolarization-activated cyclic nucleotide-gated ( $\mathrm{HCN})$ channels were reported to express in the well-known vasomotor region, rostral ventrolateral medulla (RVLM), and can be inhibited by propofol. However, whether HCN channels in RVLM contribute to propofol-induced cardiovascular depression remains unclear. We recorded the hemodynamic changes when either continuous intravenous infusions or microinjections of propofol and ZD-7288 (4-ethylphenylamino-1,2dimethyl-6-methylaminopyrimidinium chloride; HCN channel blocker) in RVLM. Expressions of HCN channels in RVLM neurons of mice of different ages were examined by quantitative real-time polymerase chain reaction and Western blotting. The effects of propofol and ZD-7288 on HCN channels and the excitability of RVLM neurons were examined by electrophysiological recording. Propofol $(1.25,2.5,5$, and $7.5 \mathrm{mg} / \mathrm{kg}$ per minute, i.v., 10 minutes) decreased mean arterial pressure (MAP) and heart rate (HR) in a concentrationdependent manner in wild-type mice that were markedly attenuated in HCN1 knockout mice. Bilateral microinjection of propofol $(1 \%, 0.1 \mu \mathrm{l})$ in RVLM caused a sharp and pronounced drop in MAP and HR values, which were abated by pretreatment with ZD-7288. In electrophysiological recording, propofol $(5,10$, and $20 \mu \mathrm{M})$ concentration-dependently inhibited HCN current, increased input resistance, decreased firing rate, and caused membrane hyperpolarization in RVLM neurons. These actions of propofol were attenuated by ZD-7288 pretreatment. The mRNA and protein level of HCN channels increased in an age-dependent manner, which may contribute to the age-dependent increase in the sensitivity to propofol. Our results indicated that the inhibition of $\mathrm{HCN}$ channels in RVLM neurons may contribute to propofol-induced cardiovascular inhibition.

\section{Introduction}

Propofol (2,6-di-isopropylphenol) is a widely used intravenous anesthetic that has quick onset, short effectiveness, and rapid recovery characteristics. However, hypotension and bradycardia are the major undesirable side effects of propofol anesthesia (Vanlersberghe and Camu, 2008; de Wit et al., 2016), especially in the elderly (Hug et al., 1993; Memtsoudis et al., 2005). Propofol at blood concentrations of $4-6 \mathrm{mg} / \mathrm{l} \mathrm{result}$ in a significant reduction in arterial blood pressure (BP) (Han et al., 2016), and anesthesia induction with propofol often reduces BP 15\%-40\% from preinduction values (Jager et al., 2015). Although the incidence of propofol-induced bradycardia is relative lower, high-dose propofol anesthesia can significantly decrease heart rate (HR) and even lead to fatal asystole (Cacheaux et al., 2005; Yang et al., 2015; de Wit et al., 2016).

This study was supported by grants 81371249 and 81571075 (to X.C.) from the National Natural Science Foundation of China (Beijing, People's Republic of China).

https://doi.org/10.1124/mol.118.111898.
However, the exact mechanisms underlying propofol-induced hypotension and bradycardia are not yet fully understood.

Various mechanisms have been proposed that account for the negative cardiovascular effects of propofol: direct myocardial depression (Hatakeyama et al., 2009; Yang et al., 2015); vasodilation (Klockgether-Radke et al., 2004; Sinha et al., 2015); reduction of baroreflex sensitivity (Memtsoudis et al., 2005; Sato et al., 2005); and decrement of catecholamine release (Xie et al., 2013; Han et al., 2016). Furthermore, evidence suggests that propofol inhibits vasomotor pressor neurons in rostral ventrolateral medulla (RVLM) (Guyenet et al., 2013), and this effect may play a pivotal role in mediating the cardiovascular effect of propofol (Yang et al., 1997, 2007; Wu et al., 2009). A previous study (Yang et al., 2007) has demonstrated that intravenous administration of propofol exerts direct inhibitory action on the firing rate of RVLM neurons. However, the detailed molecular mechanism underlying the inhibition was not well defined.

Hyperpolarization-activated cyclic nucleotide-gated (HCN) channels 1-4 are widely expressed in various tissues, including heart, central nervous system, and peripheral nervous

ABBREVIATIONS: ACSF, artificial cerebrospinal fluid; ANOVA, analysis of variance; BP, blood pressure; bpm, beats per minute; DBP, diastolic blood pressure; HCN, hyperpolarization-activated cyclic nucleotide-gated; HR, heart rate; $I_{h}$, hyperpolarization-activated cyclic nucleotide-gated current; KO, knockout; MAP, mean arterial pressure; qRT-PCR, quantitative real-time polymerase chain reaction; Ri, input resistance; RMP, resting membrane potential; RMSSD, root mean square of the difference of successive R-R intervals; RVLM, rostral ventrolateral medulla; SBP, systolic blood pressure; $\tau$, time constant; $\mathrm{V}_{1 / 2}$, half-activation voltage; $\mathrm{WT}$, wild type; ZD-7288, 4-ethylphenylamino-1,2-dimethyl-6-methylaminopyrimidinium chloride. 
system (Biel et al., 2009). The underlying HCN current $\left(I_{\mathrm{h}}\right)$ acts as a pacemaker current in cardiac and neuronal rhythmogenesis (Cacheaux et al., 2005; Chen et al., 2005). Previous studies (Kangrga and Loewy, 1995; Li et al., 1995) have indicated that $I_{\mathrm{h}}$ contributes to the pacemaker-like slow depolarization of RVLM presympathetic neurons and neurons shown a significant reduction in firing rate after blocking $I_{\mathrm{h}}$.

Moreover, propofol has been reported as a potent inhibitor of HCN1 and HCN2 channels (rather than HCN4 channels) at clinically relevant concentrations (Cacheaux et al., 2005; Chen et al., 2005). And HCN1 and HCN2 channels are implicated in anesthetic actions of propofol (e.g., mediating the amnesia and hypnosis of propofol) (Cacheaux et al., 2005; Chen et al., 2005; Ying et al., 2006). Furthermore, HCN1 and HCN2 channels at sinoatrial nodes (SANs) are reported to contribute to the negative chronotropic action of propofol at clinically relevant concentrations (Cacheaux et al., 2005). In addition, in the medulla oblongata, HCN1 and HCN2 subunits are the principal subunits; however, HCN3 and HCN4 subunits were expressed at very low levels (Notomi and Shigemoto, 2004). In the present study, we tested the hypothesis that HCN1 and HCN2 channels in RVLM neurons play a key role in mediating the adverse cardiovascular effects of propofol.

\section{Materials and Methods}

Animals. Male C57BL/6J mice and HCN1 knockout (KO) mice were used in this study. HCN1 KO mice were obtained from The Jackson Laboratory (Bar Harbor, ME) and were maintained on a mixed C57BL/6 and 129/Sv background (Stock nos. 005043 and 101045). HCN1 KO mice and wild-type (WT) littermates derived from heterozygous breeding pairs were randomly assigned to the experimental procedures. HCN1 KO mice are viable, fertile, and normal in size, and do not display any gross physical abnormalities. Mice were maintained under a 12-hour light/dark cycle with free access to standard chow and water in a temperature-controlled environment. All experimental protocols were approved by the Animal Care and Use Committee of Huazhong University of Science and Technology (Wuhan, Hubei, People's Republic of China).

Cardiovascular Responses of Propofol Infusions in WT and HCN1 KO Mice. WT and HCN1 KO mice (age, 8-12 weeks; weight, 22-28 g; $n=40$ ) were trained for at least 1 week at the same time every day to acclimate them to the mouse tail cuff BP system (IITC Lifescience, Woodland Hills, CA). Resting systolic BP (SBP), diastolic BP (DBP), and mean arterial pressure (MAP) were measured by computerized tail cuff under awake conditions (Krege et al., 1995); arterial BP was measured in 20-minute intervals during the 24-hour period. For time domain analysis, the total variances of SBP, DBP, and MAP, the S.D. values of the corresponding average BP during the 24-hour period (S.D. SBP24, S.D. DBP24, S.D. MAP24) were used to assess BP variability (Wierzbowska et al., 2012). Meanwhile, radiotelemetric ECG transmitters (ETA-F20; Data Sciences International, St. Paul, MN) were implanted subcutaneously, as described previously, and 2-hour EEG recordings were made between 10:00 and 12: $00 \mathrm{AM}$. For the time domain analysis of HR variability, mean HR, R-R interval, and two classic time domain parameters [S.D. of all normal $R-R$ intervals; root mean square of the difference of successive R-R intervals (RMSSD)] were calculated as reported previously (Fenske et al., 2013).

To assess the hemodynamic effects of propofol in this study, mice were anesthetized with continuous infusions of propofol $(1.25,2.5,5$, and $7.5 \mathrm{mg} / \mathrm{kg}$ per minute, 10 minutes) via the tail vein using a tail vein catheter connected to a model 940 Harvard Apparatus (Holliston, MA) infusion pump, the hemodynamic responses were continuously recorded for 15 minutes after infusion. The lowest values after propofol infusions were taken as the minimum MAP and HR. The percentage changes in MAP or HR were calculated using the following equation: $\%$ change $=($ baseline - minimum $) /$ baseline $\times 100$.

Drugs Microinjection in RVLM. Male mice (age, 8-12 weeks; weight, 20-30 g; $n=25$ ) were anesthetized with sodium pentobarbital (100 mg/kg, i.p.; Merck, Darmstadt, Germany). The depth of anesthesia was assessed by monitoring withdrawal reflex, BP, or respiratory responses to a firm pinch of the hind paw. Supplemental doses of sodium pentobarbital were administered as necessary (20\%-25\% of the original dose). After instrumentation, mice were placed in a stereotaxic apparatus (RWD, Shenzhen, People's Republic of China) in a prone position. A warming pad was used to maintain core body temperature at $37^{\circ} \mathrm{C}$. The jugular vein and femoral artery were cannulated with a high-fidelity microtip transducer catheter connected to a Powerlab/4SP Recording System (ADInstruments, Sydney, NSW, Australia). Two occipital bones overlying the cerebellum were carefully removed. The coordinates of the RVLM, determined using the Paxinos and Franklin atlas (Franklin and Paxinos, 2001), were $1.2-1.4 \mathrm{~mm}$ lateral to the midline, $1.6-1.8 \mathrm{~mm}$ caudal to lambda, and 5.1-5.4 mm ventral to the dorsal surface of the brain (Chen et al., 2010). Microinjections were made through multibarrelled glass micropipettes (WPI, Shanghai, People's Republic of China) using pressurized nitrogen gas, and volumes were determined by the movements of the fluid meniscus. Microinjections of L-glutamate ( $20 \mathrm{mM}, 50 \mathrm{nl}$ ) were used to functionally localize the RVLM site, and a hypertensive response of at least $20 \mathrm{mmHg}$ was identified as the positive control (Sakima et al., 2000). Microinjection of propofol was used in a $1 \%$ fat emulsion, and ZD-7288 (4-ethylphenylamino-1,2dimethyl-6-methylaminopyrimidinium chloride) (5 mM; Tocris Bioscience, Bristol, UK) was diluted in artificial cerebrospinal fluid (ACSF) (Tallapragada et al., 2016). All microinjections were bilateral, and the total volumes were $0.1 \mu \mathrm{l}$.

Histologic Identification of Microinjection Sites. At the end of experiments, $0.5 \%$ neutral red $(0.1 \mu \mathrm{l})$ was microinjected into the RVLM to mark the microinjection sites. Then mice were deeply anesthetized, and brains were removed and fixed in $4 \%$ paraformaldehyde for 2 days. The frozen brain was sectioned in the coronal brainstem plane $(50 \mu \mathrm{m})$ cut through the RVLM with a vibrating microtome (Leica, Wetzlar, Germany) and mounted on slides. Microinjection sites were identified under an optical microscope. Sections were photographed and compared with the atlas of Franklin and Paxinos (Li et al., 1995; Franklin and Paxinos, 2001).

Electrophysiological Recording from RVLM Neurons. The electrophysiological procedure was modified from a previous study ( $\mathrm{Li}$ et al., 1995). Briefly, 7- to 14-postnatal day mice were deeply anesthetized (ketamine and xylazine, $200 / 14 \mathrm{mg} / \mathrm{kg}$, i.m.) and then decapitated rapidly. The brainstem was immersed in sucrose-ACSF $\left(0-4^{\circ} \mathrm{C}\right.$ ) containing the following (in $\mathrm{mM}$ ): $26 \mathrm{NaHCO}_{3}, 1 \mathrm{NaH}_{2} \mathrm{PO}_{4}$, $2.5 \mathrm{KCl}, 5 \mathrm{MgSO}_{4}, 0.5 \mathrm{CaCl}_{2}, 10$ glucose, and 248 sucrose, equilibrated with $95 \% \mathrm{O}_{2}-5 \% \mathrm{CO}_{2}$. The brainstem slices $(250-300 \mu \mathrm{m})$ were prepared using a vibrating microtome (5100MZ; Campden, Loughborough, UK). Before recording, slices were incubated for 1-5 hours at room temperature $\left(18-25^{\circ} \mathrm{C}\right)$ in lactic acid-CSF containing the following (in $\mathrm{mM}$ ): $124 \mathrm{NaCl}, 26 \mathrm{NaHCO}_{3}, 1 \mathrm{NaH}_{2} \mathrm{PO}_{4}, 2.5 \mathrm{KCl}, 2 \mathrm{MgSO}_{4}$, $2 \mathrm{CaCl}_{2}, 10$ glucose, and 4.5 lactic acid, bubbled with $95 \% \mathrm{O}_{2}-5 \% \mathrm{CO}_{2}$ (pH 7.3-7.4). Whole-cell patch-clamp recordings were performed with an Axon Multiclamp 700B Amplifier (Molecular Devices, San Jose, CA) from visually identified RVLM neurons in the brainstem slices. The RVLM area was confirmed using the following criteria; 1 ) located caudal to the facial motor nucleus; 2) clearly visible compact of the nucleus ambiguus; and 3) presence of the rostral end of the inferior olive (Kangrga and Loewy, 1995; Li et al., 1995; Moraes et al., 2013). Pipettes (4-7 M $\Omega$ ) were filled with the following composition (in $\mathrm{mM}$ ): 112.5 potassium gluconate, $17.5 \mathrm{KCl}, 4.0 \mathrm{NaCl}, 4.0 \mathrm{MgCl}_{2}, 10 \mathrm{HEPES}$, 0.2 EGTA, $2.0 \mathrm{Mg}$-ATP, $0.3 \mathrm{Na}$-GTP, and $0.02 \%$ Lucifer yellow ( $\mathrm{pH}$ 7.3-7.4). RVLM neurons were visualized using a differential 
interference contrast microscope (BX51WI; Olympus, Tokyo, Japan) and an infrared charge-coupled device camera (IR-1000; DageMTI, Michigan City, IN). Tetrodotoxin (0.5 $\mu \mathrm{M}$; Sigma-Aldrich, St. Louis, MO) was applied to an extracellular solution to block action potentials, and a bicuculline/strychnine cocktail (both at $30 \mu \mathrm{M}$; Sigma-Aldrich) was included to inhibit $\mathrm{GABA}_{\mathrm{A}}$ and glycine receptor channels. ZD-7288 (50 $\mu \mathrm{M}$; Tocris Bioscience) and propofol (Sigma-Aldrich) were applied to block $I_{\mathrm{h}}$ in the bath solution. Propofol was prepared as a $100 \mathrm{mg} / \mathrm{ml}$ stock solution in dimethylsulfoxide and diluted into the extracellular solution at the indicated concentrations.

In voltage-clamp recordings, $I_{\mathrm{h}} \mathrm{s}$ in RVLM neurons were recorded by a series of hyperpolarization step voltage pulses $(-60$ to $-120,10 \mathrm{mV}$ increment, 3 seconds) from a holding potential of $-60 \mathrm{mV}$, followec by a voltage step of $-100 \mathrm{mV}$ to record tail currents. Tail currents were normalized and fitted with Boltzmann curves for derivation of halfactivation voltage $\left(\mathrm{V}_{1 / 2}\right)$. Time constants $(\tau)$ of $I_{\mathrm{h}}$ were calculated by fitting with a single or double exponential of the following form: $I_{\tau}=$ $I_{\mathrm{SS}}+I_{\mathrm{h}} \exp ^{-\mathrm{t} / \tau}$, where $I_{\mathrm{ss}}$ is the steady-state current (Chen et al., 2005).

Quantitative Real-Time Polymerase Chain Reaction and Western Blot. Mice at different ages (young, 2-3 weeks; adult, 8-10 weeks; aged, 40-60 weeks) were deeply anesthetized, and coronal sections $(300 \mu \mathrm{m})$ of the brainstem were obtained as described above. Then the RVLM containing the presympathetic neurons was microdissected by the Palkovits micropunch technique using a $500-\mu \mathrm{m}$-diameter punch for quantitative real-time polymerase chain reaction (qRT-PCR) and Western blot analyses (Sunderram et al., 2009). This qRT-PCR array was performed using the TaqMan Pre-Amp Master Mix Kit (Life Technologies, Carlsbad, CA) with the following probes: $\beta$-actin (NM_007393.5); HCN1 (NM_010408.3); HCN2 (NM_008226.2); and tyrosine hydroxylase (NM_009377.1). PCR was performed using the followed thermal cycling program: 1 minute at $95^{\circ} \mathrm{C}$ followed by 40 cycles of 15 seconds at $95^{\circ} \mathrm{C}, 20$ seconds at $58^{\circ} \mathrm{C}$, and 20 seconds at $72^{\circ} \mathrm{C}$, and a final extension for 20 minutes at $72^{\circ} \mathrm{C}$. The mRNA expression of each gene was normalized to the expression of the housekeeping gene $\beta$-actin, and the values in different groups were expressed relative to the data obtained from the young group using the $2^{-\Delta \Delta \mathrm{CT}}$ method.

Proteins were extracted from these punches using RIPA (radioimmunoprecipitation assay) Lysis Buffer (Beyotime Biotechnology, Jiangsu, People's Republic of China) supplemented with a protease and phosphatase inhibitor cocktail (Roche, Basel, Switzerland) and quantified by the BCA Protein Assay Kit (Beyotime Biotechnology). Forty micrograms of protein from each sample were denatured and separated by $10 \%$ SDS-PAGE, and then transferred to a polyvinylidene fluoride membrane. Primary antibodies of mouse anti-HCN1 (1:800; Abcam, Cambridge, UK), mouse anti-HCN2 (1:800; Abcam), and mouse anti- $\beta$-actin (1:3000; Abcam) were used. After incubation with a primary antibody, the membranes were then incubated with appropriate rabbit anti-mouse secondary antibody (1:5000; Abcam) for 1-1.5 hours. Immunoblotting was visualized with a SuperSignal Chemiluminescence Detection Kit (Beyotime Biotechnology) and detected using Quantity One software (Bio-Rad, Hercules, CA).

Data Acquisition and Analysis. All of the data are presented as the mean \pm S.D. SSPS version 16.0 (IBM, New York, NY) was used for all of the statistical analyses, except where noted. MAP and HR values were analyzed using ADInstrument Chart version 7.0 software. Electrophysiological data were analyzed using Clampfit version 10.5 (Molecular Devices) and Origin version 8.0 (OriginLab, Northampton, MA). Western blot data were analyzed using ImageJ. qRT-PCR data analysis was performed according to the protocol provided by Applied Biosystems (Foster City, CA). Data were compared using the Student's unpaired $t$ test or one-way or two-way analysis of variance (ANOVA); post hoc pairwise comparison used a Bonferroni correction of the $t$ test, as appropriate. $P<0.05$ was considered to be statistically significant.

\section{Results}

The Propofol-Induced Cardiovascular Depression Was Markedly Alleviated in HCN1 KO Mice. Under awake conditions, baseline MAP values were not statistically different between WT mice and HCN1 KO mice $(98.7 \pm 6.6$ vs. $103.1 \pm 7.3 \mathrm{mmHg} ; P>0.05 ; n=12$ ) (Table 1 ). In addition, the S.D. values of the average BP during the 24-hour period (SBP S.D. 24 hours, DBP S.D. 24 hours, and MAP S.D. 24 hours) were used to further assess $\mathrm{BP}$ variability with respect to time, and there were no significant differences in S.D. values for SBP 24 hours, S.D. DBP 24 hours, and S.D. MAP 24 hours during the 24-hour period between WT mice and HCN1 KO mice (Table 1). However, the baseline HR in HCN1 KO mice was significantly lower than that in WT mice $(519.2 \pm 24.9 \mathrm{vs}$. $560.1 \pm 27.4 \mathrm{bpm}$ ) (Table 1). Moreover, for time domain analysis of HR variability, time domain parameters [SD of all normal R-R intervals (SNDD), RMSSD] were markedly increased in $\mathrm{HCN} 1 \mathrm{KO}$ mice compared with WT mice (Table 1).

Next, the inhibitory effects of propofol on hemodynamic parameters (MAP and HR) between the two genotypes were examined; we used the noninvasive $\mathrm{BP}$ measurements to eliminate the effects of other anesthetics on the cardiovascular system. Continuous infusions of propofol $(1.25,2.5,5$, and $7.5 \mathrm{mg} / \mathrm{kg}$ per minute, 10 minutes) caused a significantly greater inhibition of MAP $(-10.3 \% \pm 2.9 \%,-15.8 \% \pm 3.2 \%$, $-29.4 \% \pm 3.3 \%,-51.7 \% \pm 6.3 \%$; $\Delta$ MAP: $-10.1 \pm 2.8,-15.6$ $\pm 3.2,-28.6 \pm 3.3,-51.0 \pm 6.5 \mathrm{mmHg}$, respectively; $n=6$ ) in WT mice compared with $\mathrm{HCN} 1 \mathrm{KO}$ mice (MAP: $-6.8 \% \pm$ $0.8 \%,-9.7 \% \pm 2.0 \%,-19.0 \% \pm 3.5 \%,-39.5 \% \pm 5.8 \%$; $\Delta \mathrm{MAP},-6.3 \pm 1.3,-10.0 \pm 2.1,-19.6 \pm 3.4,-40.7 \pm$ $6.2 \mathrm{mmHg}$, respectively; $n=6$ ) (Fig. 1A). Similarly, the HRs of WT mice $(-2.4 \% \pm 1.3 \%,-6.6 \% \pm 1.7 \%,-16.7 \% \pm$ $2.7 \%,-37.7 \% \pm 4.9 \% ; \Delta \mathrm{HR}:-13.2 \pm 7.3,-37.0 \pm 9.6,-93.5$ $\pm 15.1,-211.2 \pm 27.4 \mathrm{bpm}$; respectively, $n=6$ ), which respond to propofol infusions, also decreased more than those of $\mathrm{HCN} 1 \mathrm{KO}$ mice (HR: $-2.1 \% \pm 0.7 \%,-4.7 \% \pm$ $1.5 \%,-12.7 \% \pm 2.9 \%,-27.5 \% \pm 3.3 \% ; \Delta \mathrm{HR},-11.2 \pm 3.9$, $-24.4 \pm 7.6,-66.0 \pm 10.2,-142.8 \pm 16.4 \mathrm{bpm}$, respectively; $n=6$ ) (Fig. 1B)

Pretreatment with ZD-7288 Attenuated the Hemodynamic Changes of Propofol Microinjection in the RVLM. Then, we examined the cardiovascular responses to microinjections of propofol and ZD-7288 (HCN channel-selective

\section{TABLE 1}

Baseline hemodynamics parameters

Values are represented as the mean \pm S.D. The numbers in parentheses are sample size.

\begin{tabular}{lrr}
\hline & WT & HCN1 KO \\
\hline Body weight, g & $24 \pm 3.8(12)$ & $25 \pm 3.1(12)$ \\
Baseline HR, beats/min & $560.1 \pm 27.4(12)$ & $519.2 \pm 24.9(12)^{*}$ \\
R-R intervals, ms & $109.2 \pm 10.0(5)$ & $122 \pm 10.5(5)^{*}$ \\
SDNN, ms & $13.1 \pm 1.4(5)$ & $20.4 \pm 1.6(5)^{*}$ \\
RMSSD, ms & $7.4 \pm 1.7(5)$ & $18.1 \pm 1.5(5)^{*}$ \\
SBP, mmHg & $129.2 \pm 11.4(12)$ & $131.0 \pm 7.6(12)$ \\
S.D. SBP 24 h, mmHg & $5.8 \pm 0.6(6)$ & $5.4 \pm 0.6(6)$ \\
DBP mmHg & $87.4 \pm 8.0(12)$ & $85.7 \pm 8.3(12)$ \\
S.D. DBP 24 h, mmHg & $6.4 \pm 0.7(6)$ & $5.3 \pm 0.8(6)$ \\
MAP, mmHg & $98.7 \pm 6.6(12)$ & $103.1 \pm 7.3(12)$ \\
S.D. MAP 24 h, mmHg & $6.0 \pm 0.7(6)$ & $5.3 \pm 0.7(6)$ \\
\hline
\end{tabular}

SDNN, S.D. of all normal R-R intervals.

$* P<0.05$ vs. WT. 

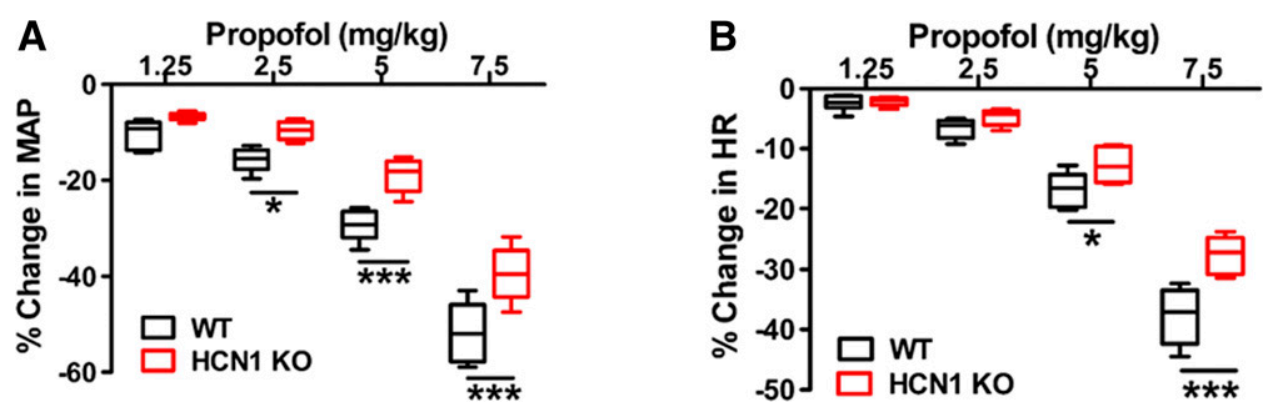

Fig. 1. Propofol caused less cardiovascular depression in HCN1 KO mice than in WT mice. Box-and-whisker plots of the effects on MAP (A) and HR (B) of continuous intravenous infusions of propofol $(1.25,2.5,5$, and $7.5 \mathrm{mg} / \mathrm{kg}$ per minute, 10 minutes) in WT mice compared with HCN1 KO mice. Values are represented as box-and-whisker plots. Error bars comprise the whiskers that extend to the maximum and minimum value data sets. Asterisks denote significant differences between HCN1 KO mice and WT mice: ${ }^{*} P<0.05$; $* * * P<0.001$, two-way ANOVA with Bonferroni post hoc $t$ test; $n=6$ in each group.

blocker) in RVLM. As illustrated in Fig. 2, identification of the RVLM area was based upon a rapid and marked increase in $\mathrm{BP}(>20 \mathrm{mmHg})$ (Fig. $2 \mathrm{~A})$ by microinjection of L-glutamate $(20 \mathrm{mM}, 50 \mathrm{nl})$ and histologic verification, as shown in Fig. 2F. Microinjections of propofol $(1 \%, 0.1 \mu \mathrm{l})$ and ZD-7288 $(5 \mathrm{mM}, 0.1 \mu \mathrm{l})$ provoked a significant decrease in MAP values $(-36.0 \pm 3.6,-8.0 \pm 1.3 \mathrm{mmHg}$, respectively; $n=6$ ) (Fig. $2 \mathrm{G}$ ) and $\mathrm{HR}$ values $(-43.3 \pm 4.9,-6.4 \pm 0.9 \mathrm{bpm}$, respectively; $n=6$ ) (Fig. $2 \mathrm{H}$ ). A diminished response to propofol microinjection in RVLM was caused by pretreatment with ZD-7288 (Fig. 2, G and H). Our results demonstrated that HCN channels contribute to the cardiovascular effects of propofol, which related to the effects in RVLM.

ZD-7288 Pretreatment Abated Propofol-Induced Inhibitory Electrophysiological Effects in RVLM Presympathetic Neurons. To further investigate the molecular basis of propofol-induced cardiovascular inhibition, we analyzed whether HCN channels participate in the inhibitory
A

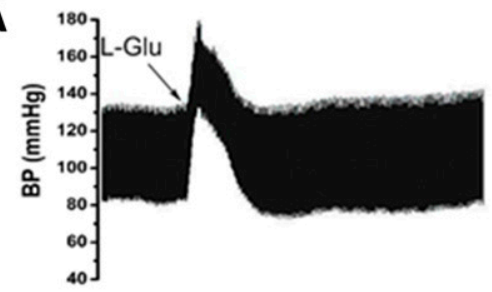

C

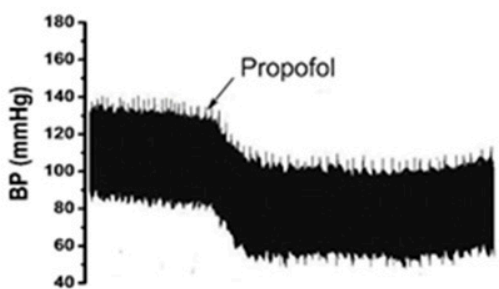

E

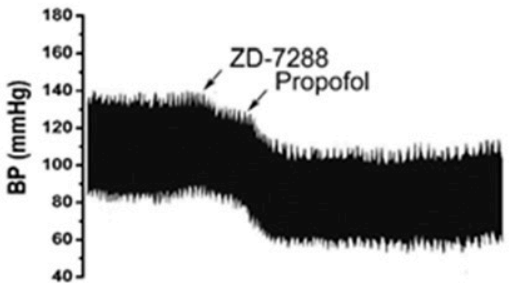

G

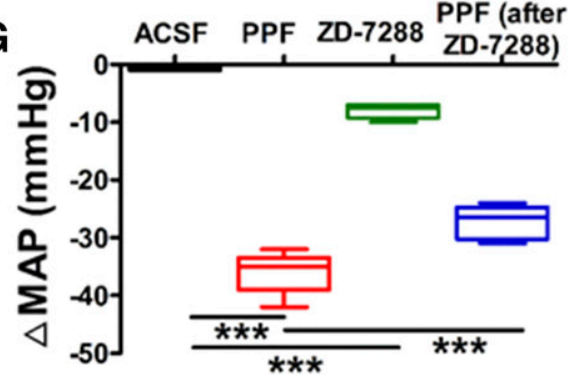

B

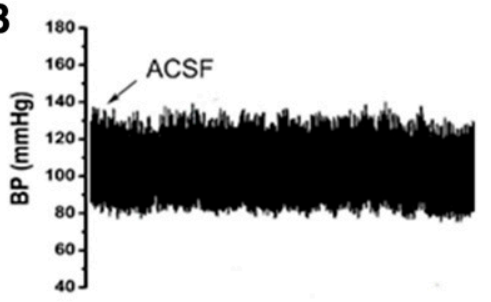

D

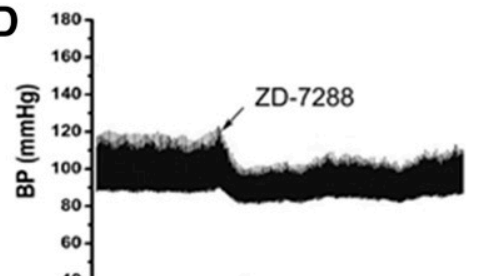

$\mathbf{F}$
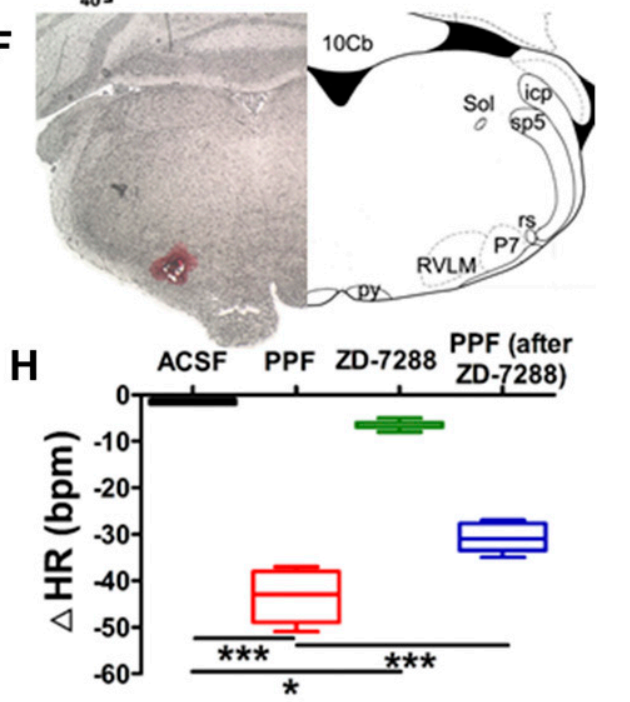

Fig. 2. Hemodynamic effects of bilateral microinjection of drugs into the RVLM. The effects of the microinjection of L-glutamate $(20 \mathrm{mM}, 50 \mathrm{nl}$; A), ACSF (0.1 $\mu \mathrm{l} ; \mathrm{B})$, propofol (PPF) (1\%, $0.1 \mu \mathrm{l}$; C), and ZD-7288 (5 mM, $0.1 \mu \mathrm{l}$; D) into the RVLM on BP. (E) Pretreatment with ZD-7288 attenuated the effect of propofol microinjection into the RVLM on BP. (F) Histologic identification of microinjection sites. $4 \mathrm{~V}$, fourth ventricle; icp, inferior cerebellar peduncle; P7, perifacial zone; Py, pyramidal tract; sol, solitary tract; sp5, spinal trigeminal tract; 10cb, 10th cerebellar lobule. Box-and-whisker plots of the effects of microinjection drugs on the changes in MAP $(\mathrm{G})$ and $\mathrm{HR}(\mathrm{H}) .{ }^{*} P<$ $0.05 ; * * * P<0.001$, one-way ANOVA with Bonferroni post hoc $t$ test; $n=7$ in each group. 
effects of propofol using voltage clamp and current clamp. An example of a Lucifer yellow-stained RVLM neuron and its intrinsic electrophysiological characteristic are shown in Fig. 3A; the perikarya of RVLM neurons were rhombic, fusiform, or triangular in shape, and neurons had a relatively simple dendritic trees consisting of three to six primary dendrites (Fig. 3A). Under hyperpolarizing step voltage pulses ( -60 to $-120,10-\mathrm{mV}$ increment, 3 seconds) from a holding potential of $-60 \mathrm{mV}$, RVLM presympathetic neurons exhibited a pronounced hyperpolarization-activated inward current, which starts be activated at approximately -60 to $-70 \mathrm{mV}$ with a peak at $-120 \mathrm{mV}(200-300 \mathrm{pA})$, with a $\mathrm{V}_{1 / 2}$ value of $-95.9 \pm 4.9 \mathrm{mV}$, a slope factor of $-7.2 \pm 0.6 \mathrm{mV}$, a $\tau$ value of $I_{\mathrm{h}}$ at $-120 \mathrm{mV}$ of $276.3 \pm 45.2$ milliseconds a $\tau_{\text {fast }}$ (the fast component determined from biexponential fits) value of $122.9 \pm 37.9$ milliseconds, and a $\tau_{\text {slow }}$ (the slow component determined from biexponential fits) value of $952.4 \pm 380.6$ milliseconds (Fig. 3B). ZD-7288 (50 $\mu \mathrm{M})$ almost abolished this current (Fig. 3B) and markedly increased the input resistance (Ri; 60\%) (Fig. 4C). Propofol (5, 10, $20 \mu \mathrm{M})$ inhibited $I_{\mathrm{h}}$ and caused a significant hyperpolarizing shift in $\mathrm{V}_{1 / 2}$ in a concentration-dependent manner (Fig. 4, B and D).
The maximal inhibition of propofol $(0-40 \mu \mathrm{M})$ on $I_{\mathrm{h}}$ was $-59.8 \% \pm 7.6 \%$ (Fig. 4B). Propofol administration $(20 \mu \mathrm{M})$ resulted in a significant increase in $\mathrm{Ri}$ (Fig. 4C). However, propofol had no effects on $\mathrm{Ri}$ in RVLM neurons after the elimination of $I_{\mathrm{h}}$ by ZD-7288 (Fig. 4C), suggesting that the propofol-induced increase in $\mathrm{Ri}$ was caused by the inhibition of $I_{\mathrm{h}}$.

Moreover, under current-clamp recording, ZD-7288 reduced the spontaneous firing rate of RVLM neurons (from $4.5 \pm 1.1$ to $3.5 \pm 0.8 \mathrm{~Hz} ; P=0.02 ; n=11$ ) (Fig. 5 , A and B), with a slower slope of ramp potentials and remarkable hyperpolarization of resting membrane potential (RMP) $(-9.1 \pm 1.9 \mathrm{mV}$, $n=7$ ) (Fig. 5, B and C). Propofol (5, 10, and $20 \mu \mathrm{M})$ dosedependently reduced the firing rate and evoked moderate membrane hyperpolarization (Fig. 5, B and C). After ZD-7288 pretreatment, the $\mathrm{EC}_{50}$ value of the firing rate inhibition of propofol shifted from $8.4 \pm 0.9$ to $11.2 \pm 1.2 \mu \mathrm{M}(n=3)$ (Fig. 5D), and propofol (20 $\mu \mathrm{M})$ failed to evoke a significant membrane hyperpolarization after $I_{\mathrm{h}}$ was eliminated by ZD-7288 (Fig. 5, A and E). Thus, the inhibition of $I_{\mathrm{h}}$ mediated membrane hyperpolarization by propofol administration in RVLM neurons.
A

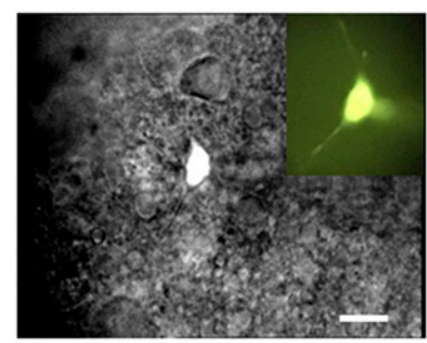

B

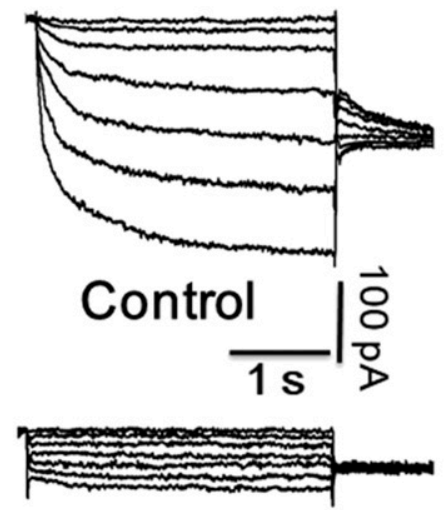

ZD-7288
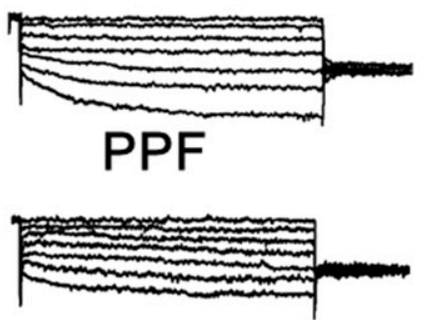

PPF (after ZD-7288)

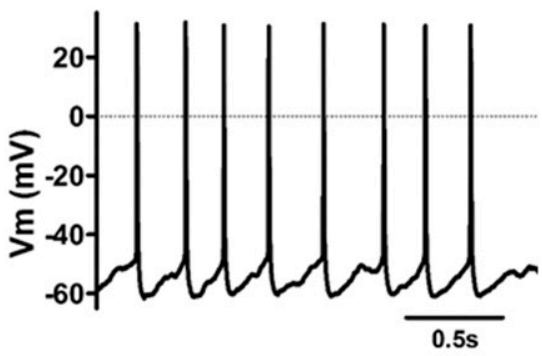

C

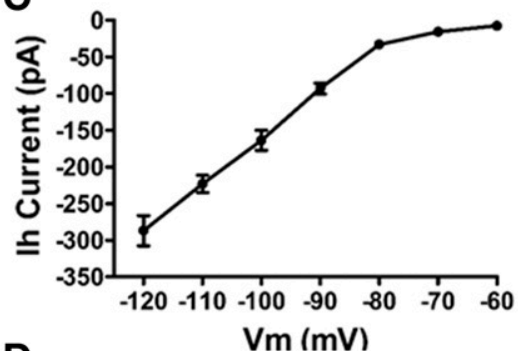

D
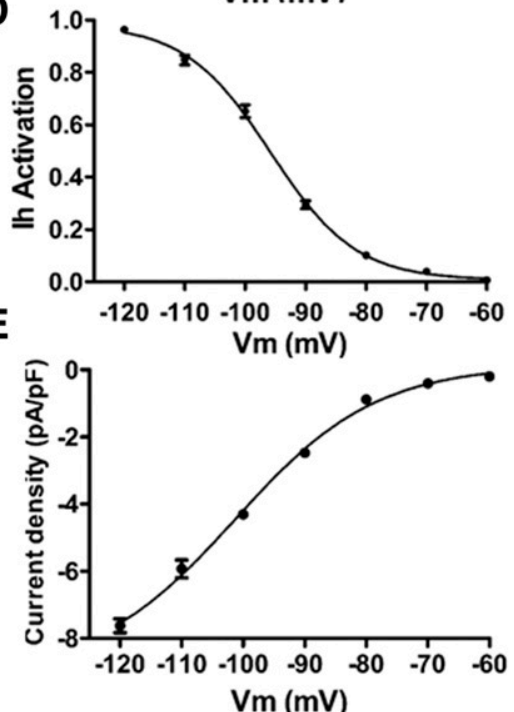

Fig. 3. Propofol and ZD-7288 inhibited $I_{\mathrm{h}}$ in the RVLM presympathetic neurons. (A) The morphology (left) and electrophysiology (right) characteristic of a typical RVLM neuron. Scale bar, $20 \mu \mathrm{M}$. (B) Voltage-clamp recording ( -60 to $-120 \mathrm{mV},-10 \mathrm{mV}$ increment) of $I_{\mathrm{h}}$ under control conditions and after the administration of ZD-7288 $(50 \mu \mathrm{M})$, propofol $(20 \mu \mathrm{M})$, and propofol $(20 \mu \mathrm{M})$ after ZD-7288 pretreatment $(50 \mu \mathrm{M}, 5 \mathrm{~min})$. (C) Current-voltage relationship of the steady-state portion of the averaged $I_{\mathrm{h}}$ values. (D) $I_{\mathrm{h}}$ activation curve (Boltzman fitted) showing the voltage dependence of the inward current. (E) The current density (Boltzman fitted) curve of $I_{\mathrm{h}}$ in RVLM neurons. PPF, propofol. Values are presented as the mean \pm S.D.; $n=7$ in each group. 
A
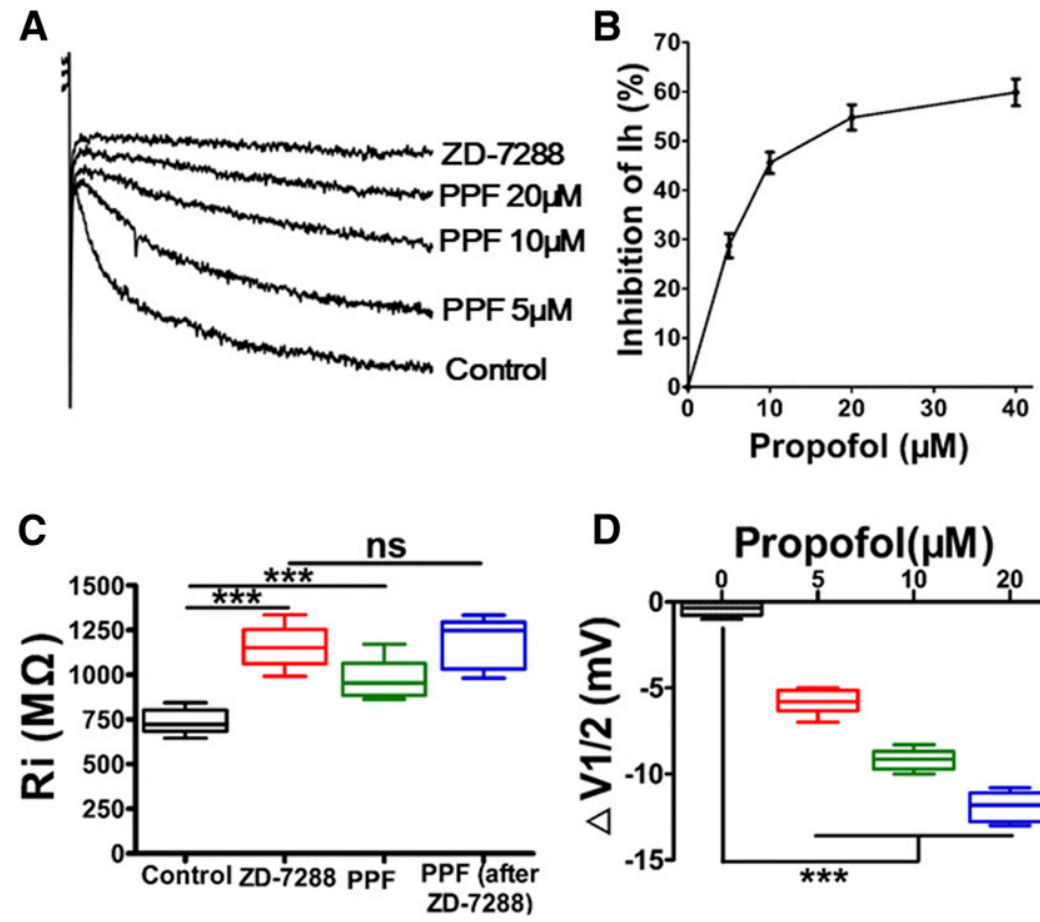

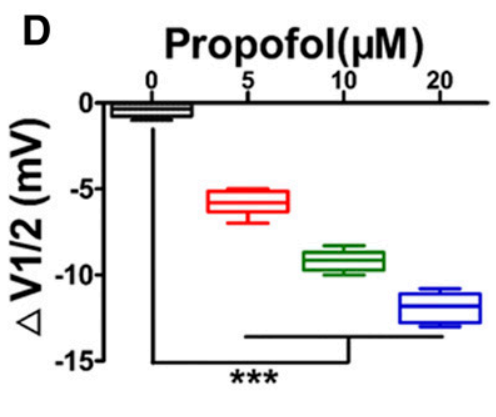

Fig. 4. Effects of propofol on Ri and half-activation in RVLM neurons. (A) The comparison of $I_{\mathrm{h}}$ amplitude at $-120 \mathrm{mV}$ under control conditions and after ZD-7288 $(50 \mu \mathrm{M})$ and propofol $(5,10,20 \mu \mathrm{M})$ administration. (B) Propofol $(0,5,10,20,40 \mu \mathrm{M})$ concentration dependently inhibited $I_{\mathrm{h}}$ in the RVLM presympathetic neurons. (C) Box-and-whisker plots of the effects of ZD-7288 $(50 \mu \mathrm{M})$, propofol $(20 \mu \mathrm{M})$, and propofol $(20 \mu \mathrm{M})$ after ZD-7288 pretreatment $(50 \mu \mathrm{M}$, 5 minutes) on the Ri of RVLM neurons. (D) Box-and-whisker plot of the effects of propofol $(0,5,10,20 \mu \mathrm{M})$ on the $\Delta \mathrm{V}_{1 / 2}$ of $I_{\mathrm{h}}$ in RVLM neurons. PPF, propofol. Values are presented as the mean \pm S.D. ${ }^{*} P<0.05 ; * * * P<0.001$, one-way ANOVA with Bonferroni post hoc $t$ test. ns, no significance. $n=7$ in each group.
Age-Related Increase of HCN Channels Contributes to the Increasing Sensitivity to Propofol. Propofol causes hypotension and bradycardia more frequently in elderly patients than in young adult patients (Hug et al., 1993; Memtsoudis et al., 2005), and altered expressions of HCN channels can affect the sensitivity to propofol; and it remains unclear whether the increased sensitivity to propofol in the elderly can be attributed to the age-related changes of HCN channels in RVLM neurons. Thus, in this study, we used qRT-PCR and Western blotting to determine the effects of aging on the mRNA and protein expressions of HCN1 and HCN2 channels. To further confirm that HCN channels in RVLM contribute to the cardiovascular effects of propofol, we investigated the changes in expression of HCN channels in RVLM neurons.

As shown in Fig. 6, A and B, the results of qRT-PCR revealed a progressive and significant increase in HCN channels mRNA level with ages. In comparison with young mice, HCN1 mRNA in RVLM increased about $33 \%$ in adult mice, and $95 \%$ in aged mice (Fig. 6A). HCN2 mRNA also increased $44 \%$ in adult mice, and $80 \%$ in aged mice (Fig. 6B). Likewise, the protein levels of HCN channels also displayed an agerelated trend for increases. Compared with young mice, HCN1 protein in RVLM of adult and aged mice increased approximately $70 \%$ and $110 \%$, respectively (Fig. 6C). HCN2 protein levels in RVLMs in adult and aged mice also increased $\sim 41 \%$ and $180 \%$, respectively (Fig. $6, \mathrm{C}$ and D).

\section{Discussion}

This study has implications for understanding both the neuropharmacology of propofol action and the molecular basis of propofol-induced hypotension and bradycardia. First, the HCN1 channel was confirmed to be a key target for propofolinduced cardiovascular inhibition. Second, the central inhibitory action of propofol was further substantiated by the dramatic drop in MAP and HR after microinjection of ZD-7288 into RVLM, and a diminished response to propofol microinjection was caused by ZD-7288 pretreatment. Furthermore, in the electrophysiological recording, propofol and ZD-7288 inhibited $I_{\mathrm{h}}$ and suppressed the autoactivity of RVLM presympathetic neurons. ZD-7288 pretreatment attenuated the inhibitory electrophysiological effects of propofol on RVLM neurons. Last, both the mRNA and protein levels of HCN channels in RVLM neurons increased in an age-dependent manner, which are changes that are expected to account for the increased cardiovascular sensitivity to propofol. Taken together, the inhibition of HCN channels in RVLM neurons contribute to propofolinduced cardiovascular inhibition.

In this study, there was no significant difference in MAP values between WT and HCN1 KO mice, but HCN1 KO mice displayed a slower $\mathrm{HR}$ and increased $\mathrm{HR}$ variability compared with WT mice, a difference that was consistent with the results from previous studies that HCN1-deficient mice display congenital SAN dysfunction characterized by bradycardia (Fenske et al., 2013). Previous studies have reported that when propofol is infused at $2.5-10 \mathrm{mg} / \mathrm{kg}$ per minute, the peak total serum concentrations of propofol were approximately 20-30 $\mu \mathrm{g} / \mathrm{g}$ (Larsson and Wahlstrom, 1998), which correspond with 112$170 \mu \mathrm{M}$. Accordingly, the concentrations of propofol used in our study were similar to those reported in previous studies (Larsson and Wahlstrom, 1994, 1998; Sinha et al., 2015) and are well within the clinically relevant range $(8-180 \mu \mathrm{M})$ (Higuchi et al., 2003). After continuous intravenous infusions of propofol, HCN1 KO mice displayed less cardiovascular inhibition on MAP and HR to intravenous infusions of propofol than WT mice. These results demonstrated that HCN1 channels contribute to the cardiovascular inhibition of propofol.

The RVLM is well known as a pivotal cardiovascular integration center, which is crucial to maintain the baseline 
A
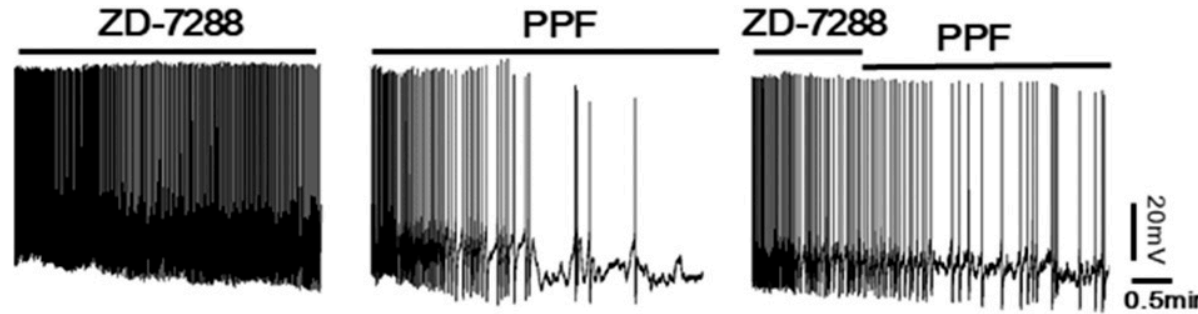

B

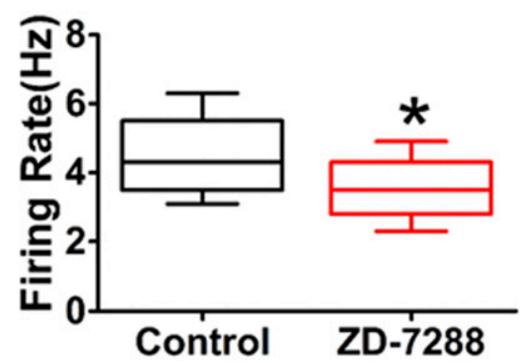

D

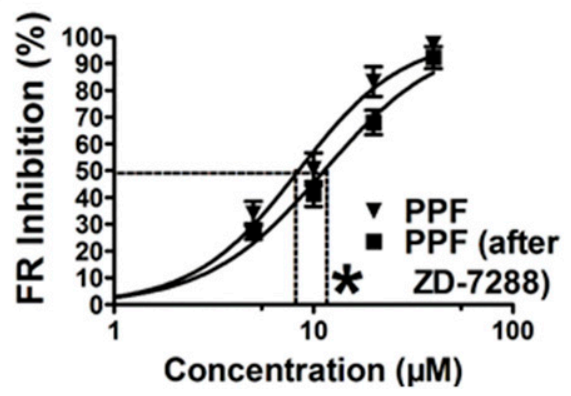

C

E

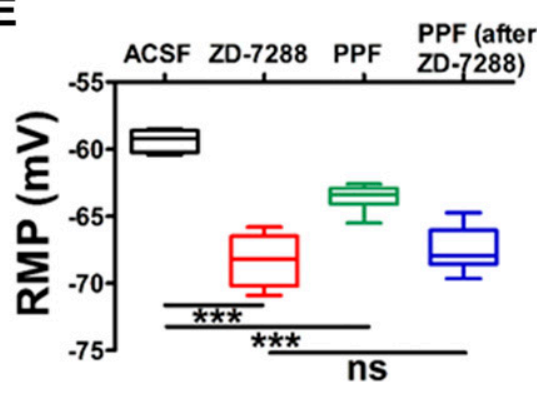

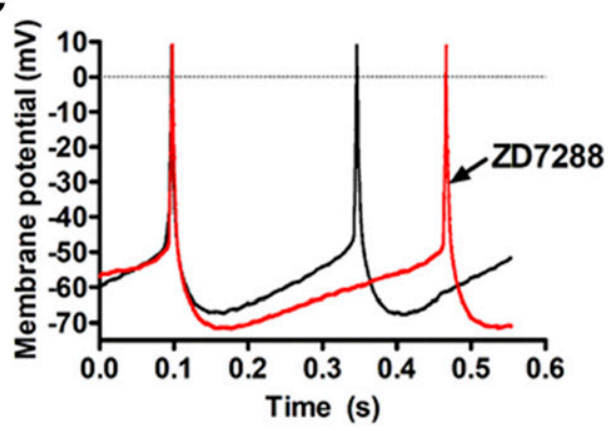

Fig. 5. Effect of ZD-7288 and propofol on spontaneous firing rate (FR) and RMP in RVLM neurons. (A) The effects of ZD-7288 (50 $\mu \mathrm{M})$, propofol $(20 \mu \mathrm{M})$, and propofol (20 $\mu \mathrm{M})$ after $\mathrm{ZD}-7288$ pretreatment (50 $\mu \mathrm{M}, 5$ minutes) on the spontaneous FR and RMP of RVLM neurons. (B) Boxand-whisker plot of the effect of ZD-7288 (50 $\mu \mathrm{M})$ on the firing rate of RVLM neurons $(* P<0.05$ by two-tailed unpaired $t$ test). (C) ZD-7288 (50 $\mu \mathrm{M})$ modulated RVLM neurons by prolonging the interspike interval and hyperpolarizing the membrane potential. (D) Pretreatment with ZD-7288 attenuated the inhibition of propofol on $\mathrm{FR}\left(\mathrm{EC}_{50}\right.$ range, $8.4 \pm 0.9$ to $11.2 \pm 1.2 \mu \mathrm{M}) .{ }^{*} P<0.05$ by two-way ANOVA, $n=3$. (E) Box-and-whisker plot of the effects of ZD-7288 and propofol on RMPs of RVLM neurons. PPF, propofol. $* P<0.05 ; * * * P<0.001$, one-way ANOVA with Bonferroni post hoc $t$ test. ns, no significance. $n=7$ in each group. arterial pressure and HR (Guyenet et al., 2013). In our study, both propofol and ZD-7288 evoked a significant drop in MAP and HR, and ZD-7288 pretreatment significantly attenuated the hemodynamic effects of propofol. Moreover, interestingly, like propofol, clonidine (Knaus et al., 2007), dexmedetomidine (Yang et al., 2014), and ketamine (Chen et al., 2009) are potent HCN channel blockers, and microinjections of these drugs have also been reported to directly produce a dramatic attenuation in MAP and HR (Hong et al., 1992; Schreihofer and Guyenet, 2000; Wang et al., 2001), suggesting that RVLM may be the pivotal site of the cardiovascular effects of anesthetics, and these anesthetics achieve the cardiovascular effects via inhibition of HCN channels in RVLM neurons.

According to the electrophysiological recording results, $I_{\mathrm{h}}$ was suggested to serve as a pacemaker current that plays a key role in regulating the spontaneous firing activity of RVLM neurons (Kangrga and Loewy, 1995; Li et al., 1995). However, as seen in Figs. 2 and 5, ZD-7288 pretreatment failed to abolish the inhibitory effects of propofol on RVLM neurons, which suggests that the effects of propofol may also be mediated by other targets (e.g., $\mathrm{GABA}_{\mathrm{A}}$ receptor). The microinjection of GABA into RVLM has been reported (Lacerda et al., 2003) to reduce a significant fall in MAP and HR, and we confirmed that HCN channels in RVLM neurons partially mediated the adverse cardiovascular effects of propofol. Among the four HCN channel subunits, HCN1 and HCN2 subunits are predominantly distributed in medulla oblongata (Notomi and Shigemoto, 2004; Milligan et al., 2006). Additionally, the activation of the HCN2 channel is highly accelerated by the increase of cytoplasmic cAMP (Biel et al., 2009), and the activation of cAMP-dependent pathways in RVLM neurons evoked sympathoexcitation and a pressor effect. Microinjection of cAMP analogs (8-Br-cAMP) evoked an increase in MAP (Tallapragada et al., 2016). In neonatal RVLM brain slice preparations, 8-Br-cAMP and forskolin (an adenylyl cyclase activator) increased the firing rate of RVLM presympathetic neurons in the presence of tetrodotoxin (Sun and Guyenet, 1990). It is possible that both $\mathrm{HCN} 1$ and $\mathrm{HCN} 2$ channels are jointly participate in maintaining the neuronal excitability of RVLM neurons.

Similarly, except for RVLM neurons, HCN1 and HCN2 channels expressed in other area might also contribute to the cardiovascular effects of propofol. As previously reported (Cacheaux et al., 2005), HCN channels (HCN1 and HCN2) at the SAN contribute to the negative chronotropic action of propofol at clinically relevant concentrations. Since HCN channels conduct a depolarization current, the age-related increase in mRNA and protein expression in HCN1 and HCN2 channels exerts its influences on the neuronal excitability of RVLM neurons, which may result in an increased sensitivity to propofol-induced cardiovascular inhibition (Krassioukov et al., 1993; Memtsoudis et al., 2005). Because of the great 

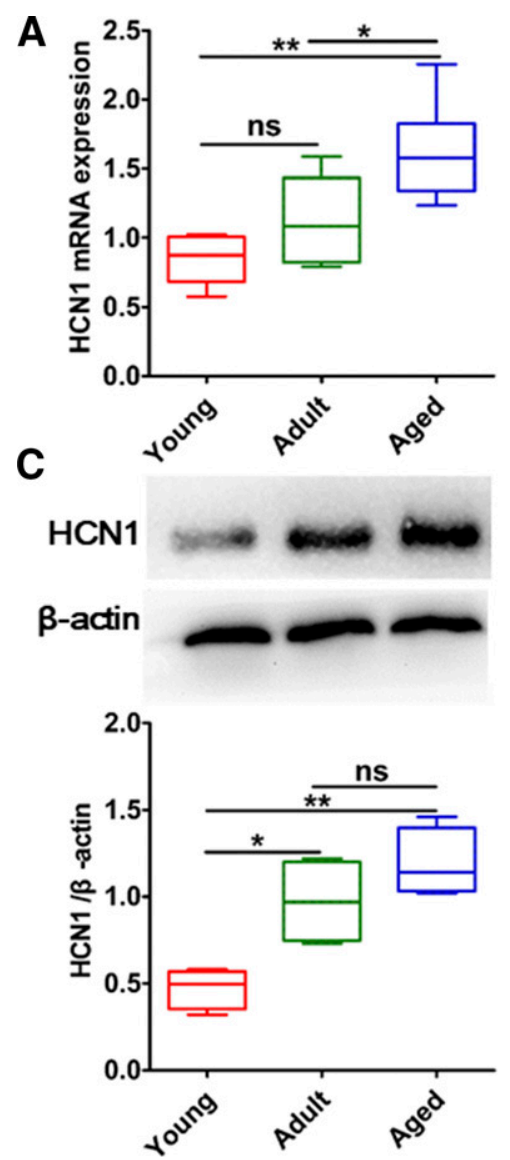
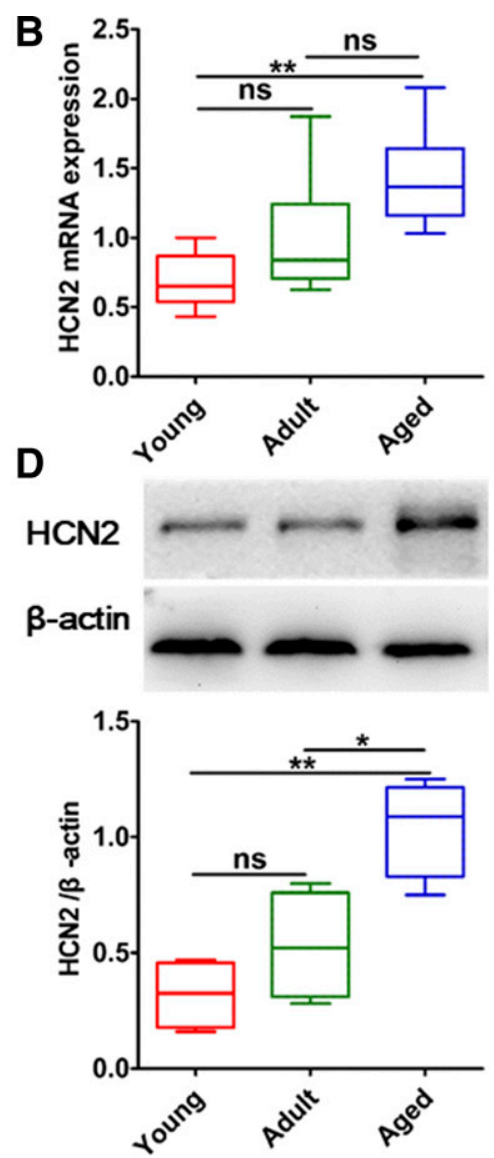

Fig. 6. Age-related increase in the mRNA and protein levels of HCN channels in RVLM neurons. Box-and-whisker plots of age-related increases in the mRNA level of HCN1 $(n=6 ; \mathrm{A})$ and $\mathrm{HCN} 2(n=6 ; \mathrm{B})$ channels during development. Representative Western blot of the protein levels of HCN1 (C) and HCN2 (D) channels. And quantitative analysis was determined by the ratio of HCN1 or HCN2 and $\beta$-actin immunoreactivity $(n=3)$. $* P<0.05 ; * * P<0.01$, one-way ANOVA with Bonferroni post hoc $t$ test. ns, no significance. challenges in electrophysiological recording in RVLM neurons from adult and aged mice, the most relevant studies were performed in the slices of neonatal and juvenile rats. Despite that, it has been reported (Almado et al., 2014) that the intrinsic firing rate of RVLM neurons in juvenile rats $(9.73 \pm 1.06 \mathrm{~Hz})$ is significantly higher than that of neonatal rats $(4.3 \pm 1.7 \mathrm{~Hz})$. However, the detailed effects of the agerelated alternation of $\mathrm{HCN} 1$ and $\mathrm{HCN} 2$ channels on the electrophysiological properties of RVLM neurons need further investigation.

This study has some limitations. First, because of the lack of HCN1 and HCN2 double-KO mice, we failed to use the HCN channels from knockout mice in all experiments. And ZD-7288 is not a subtype-specific HCN channel blocker. It would be more convincing if selective blockers (e.g., MEL57A) were used in further studies (Del Lungo et al., 2012). Second, in the microinjection procedure, the mice were deeply anesthetized with pentobarbital; hence, the hemodynamic changes of microinjections cannot fully reflect the effects of the drugs. If possible, an optogenetic approach could be more convincing to explore the role of $\mathrm{HCN}$ channels in conscious mice. At last, in this study, because of the great challenge of continuous intravenous infusion in young mice (2-3 weeks of age), we failed to demonstrate an age-dependent difference in propofolinduced cardiovascular depression in this animal model.

In conclusion, the inhibition of RVLM may contribute to propofol-induced cardiovascular inhibition, and HCN1 and HCN2 channels in these neurons may play a vital role in mediating these actions. This finding may have a guiding significance for us in the development of new anesthetic agents that have fewer effects on the cardiovascular system.

\section{Acknowledgments}

We thank Shaofang Shu (Department of Anesthesiology, Union Hospital of Tongji Medical College, Huazhong University of Science and Technology) for providing technical assistance.

\section{Authorship Contributions}

Participated in research design: $\mathrm{Hu}, \mathrm{Yao}$, Chen.

Conducted experiments: $\mathrm{Hu}, \mathrm{Wu}, \mathrm{Gao}$.

Performed data analysis: $\mathrm{Hu}$, Jia, Li, Ouyang.

Wrote or contributed to the writing of the manuscript: $\mathrm{Hu}$, Chen.

\section{References}

Almado CE, Leão RM, and Machado BH (2014) Intrinsic properties of rostral ventrolateral medulla presympathetic and bulbospinal respiratory neurons of juvenile rats are not affected by chronic intermittent hypoxia. Exp Physiol 99:937-950.

Biel M, Wahl-Schott C, Michalakis S, and Zong X (2009) Hyperpolarization-activated cation channels: from genes to function. Physiol Rev 89:847-885.

Cacheaux LP, Topf N, Tibbs GR, Schaefer UR, Levi R, Harrison NL, Abbott GW, and Goldstein PA (2005) Impairment of hyperpolarization-activated, cyclic nucleotide-gated channel function by the intravenous general anesthetic propofol. $J$ Pharmacol Exp Ther 315:517-525.

Chen D, Hazelwood L, Walker LL, Oldfield BJ, McKinley MJ, and Allen AM (2010) Changes in angiotensin type 1 receptor binding and angiotensin-induced pressor responses in the rostral ventrolateral medulla of angiotensinogen knockout mice. Am J Physiol Regul Integr Comp Physiol 298:R411-R418.

Chen X, Shu S, and Bayliss DA (2005) Suppression of ih contributes to propofolinduced inhibition of mouse cortical pyramidal neurons. J Neurophysiol 94: $3872-3883$.

Chen X, Shu S, and Bayliss DA (2009) HCN1 channel subunits are a molecular substrate for hypnotic actions of ketamine. J Neurosci 29:600-609.

Del Lungo M, Melchiorre M, Guandalini L, Sartiani L, Mugelli A, Koncz I, Szel T, Varro A, Romanelli MN, and Cerbai E (2012) Novel blockers of hyperpolarizationactivated current with isoform selectivity in recombinant cells and native tissue. Br J Pharmacol 166:602-616. 
de Wit F, van Vliet AL, de Wilde RB, Jansen JR, Vuyk J, Aarts LP, de Jonge E, Veelo DP, and Geerts BF (2016) The effect of propofol on haemodynamics: cardiac output, venous return, mean systemic filling pressure, and vascular resistances. $\mathrm{Br} J$ Anaesth 116:784-789.

Fenske S, Krause SC, Hassan SI, Becirovic E, Auer F, Bernard R, Kupatt C, Lange P, Ziegler T, Wotjak CT, et al. (2013) Sick sinus syndrome in HCN1-deficient mice. Circulation 128:2585-2594.

Franklin KBJ and Paxinos G (2001) The Mouse Brain in Stereotaxic Coordinates, 2nd ed, Academic Press, San Diego.

Guyenet PG, Stornetta RL, Bochorishvili G, Depuy SD, Burke PG, and Abbott SB (2013) C1 neurons: the body's EMTs. Am J Physiol Regul Integr Comp Physiol 305 R187-R204.

Han L, Fuqua S, Li Q, Zhu L, Hao X, Li A, Gupta S, Sandhu R, Lonart G, and Sugita $\mathrm{S}$ (2016) Propofol-induced inhibition of catecholamine release is reversed by maintaining calcium influx. Anesthesiology 124:878-884.

Hatakeyama N, Sakuraya F, Matsuda N, Kimura J, Kinoshita H, Kemmotsu O, Yamazaki M, and Hattori Y (2009) Pharmacological significance of the blocking action of the intravenous general anesthetic propofol on the slow component of cardiac delayed rectifier K+ current. J Pharmacol Sci 110:334-343.

Higuchi H, Funahashi M, Miyawaki T, Mitoh Y, Kohjitani A, Shimada M, and Matsuo R (2003) Suppression of the hyperpolarization-activated inward current contributes to the inhibitory actions of propofol on rat CA1 and CA3 pyramidal neurons. Neurosci Res 45:459-472.

Hong M, Milne B, Loomis C, and Jhamandas K (1992) Stereoselective effects of central alpha 2-adrenergic agonist medetomidine on in vivo catechol activity in the rat rostral ventrolateral medulla (RVLM). Brain Res 592:163-169.

Hug CC Jr, McLeskey CH, Nahrwold ML, Roizen MF, Stanley TH, Thisted RA Walawander CA, White PF, Apfelbaum JL, Grasela TH, et al. (1993) Hemodynamic effects of propofol: data from over 25,000 patients. Anesth Analg 77 (4 Suppl): S21-S29.

Jager MD, Aldag JC, and Deshpande GG (2015) A presedation fluid bolus does not decrease the incidence of propofol-induced hypotension in pediatric patients. Hosp Pediatr 5:85-91.

Kangrga IM and Loewy AD (1995) Whole-cell recordings from visualized C1 adrenergic bulbospinal neurons: ionic mechanisms underlying vasomotor tone. Brain Res 670:215-232

Klockgether-Radke AP, Schulze H, Neumann P, and Hellige G (2004) Activation of the $\mathrm{K}+$ channel $\mathrm{BK}(\mathrm{Ca})$ is involved in the relaxing effect of propofol on coronary arteries. Eur J Anaesthesiol 21:226-230.

Knaus A, Zong X, Beetz N, Jahns R, Lohse MJ, Biel M, and Hein L (2007) Direct inhibition of cardiac hyperpolarization-activated cyclic nucleotide-gated pacemaker channels by clonidine. Circulation 115:872-880.

Krassioukov AV, Gelb AW, and Weaver LC (1993) Action of propofol on central sympathetic mechanisms controlling blood pressure. Can J Anaesth 40 (8): 761-769.

Krege JH, Hodgin JB, Hagaman JR, and Smithies O (1995) A noninvasive computerized tail-cuff system for measuring blood pressure in mice. Hypertension 25 $1111-1115$.

Lacerda JE, Campos RR, Araujo GC, Andreatta-Van Leyen S, Lopes OU, and Guertzenstein PG (2003) Cardiovascular responses to microinjections of GABA or anesthetics into the rostral ventrolateral medulla of conscious and anesthetized rats. Braz J Med Biol Res 36:1269-1277.

Larsson JE and Wahlström G (1994) Optimum rate of administration of propofol for induction of anaesthesia in rats. Br J Anaesth 73:692-694.

Larsson JE and Wahlström G (1998) The influence of age and administration rate on the brain sensitivity to propofol in rats. Acta Anaesthesiol Scand 42:987-994.

Li YW, Bayliss DA, and Guyenet PG (1995) C1 neurons of neonatal rats: intrinsic beating properties and alpha 2-adrenergic receptors. Am J Physiol 269: R1356-R1369.

Memtsoudis SG, The AH, and Heerdt PM (2005) Autonomic mechanisms in the agerelated hypotensive effect of propofol. Anesth Analg 100:111-115.

Milligan CJ, Edwards IJ, and Deuchars J (2006) HCN1 ion channel immunoreactivity in spinal cord and medulla oblongata. Brain Res 1081:79-91.
Moraes DJ, da Silva MP, Bonagamba LG, Mecawi AS, Zoccal DB, Antunes-Rodrigues J, Varanda WA, and Machado BH (2013) Electrophysiological properties of rostral ventrolateral medulla presympathetic neurons modulated by the respiratory network in rats. J Neurosci 33:19223-19237.

Notomi T and Shigemoto R (2004) Immunohistochemical localization of Ih channe subunits, HCN1-4, in the rat brain. J Comp Neurol 471:241-276.

Sakima A, Yamazato M, Sesoko S, Muratani H, and Fukiyama K (2000) Cardiovascular and sympathetic effects of L-glutamate and glycine injected into the rostral ventrolateral medulla of conscious rats. Hypertens Res 23 (6):633-641.

Sato M, Tanaka M, Umehara S, and Nishikawa T (2005) Baroreflex control of heart rate during and after propofol infusion in humans. Br J Anaesth 94:577-581.

Schreihofer AM and Guyenet PG (2000) Role of presympathetic C1 neurons in the sympatholytic and hypotensive effects of clonidine in rats. Am J Physiol Regul Integr Comp Physiol 279:R1753-R1762.

Sinha S, Sinharoy P, Bratz IN, and Damron DS (2015) Propofol causes vasodilation in vivo via TRPA1 ion channels: role of nitric oxide and BKCa channels. PLoS One 10:e 0122189 .

Sun MK and Guyenet PG (1990) Excitation of rostral medullary pacemaker neurons with putative sympathoexcitatory function by cyclic AMP and beta-adrenoceptor agonists 'in vitro'. Brain Res 511:30-40.

Sunderram J, Semmlow J, Thakker-Varia S, Bhaumik M, Hoang-Le O, and Neubauer JA (2009) Heme oxygenase-1-dependent central cardiorespiratory adaptations to chronic hypoxia in mice. Am J Physiol Regul Integr Comp Physiol 297:R300-R312.

Tallapragada VJ, Hildreth CM, Burke PG, Raley DA, Hassan SF, McMullan S, and Goodchild AK (2016) Tonically active cAMP-dependent signaling in the ventrolateral medulla regulates sympathetic and cardiac vagal outflows. J Pharmacol Exp Ther 356:424-433.

Vanlersberghe C and Camu F (2008) Propofol in Modern Anesthetics. Handbook of Experimental Pharmacology (Schüttler J and Schwilden $\mathrm{H}$ eds) vol 182, pp 227-252. Springer, New York.

Wang WZ, Rong WF, Wang JJ, and Yuan WJ (2001) Effect of ketamine on presympathetic neurons in rostral ventrolateral medulla of rats. Acta Pharmacol Sin 22:97-102.

Wierzbowska J, Wierzbowski R, Stankiewicz A, Siesky B, and Harris A (2012) Cardiac autonomic dysfunction in patients with normal tension glaucoma: 24 -h heart rate and blood pressure variability analysis. Br J Ophthalmol 96:624-628.

Wu WC, Yang C-Y, and Chai C-Y (2009) Modulation of propofol on the effects of blood pressure and firing activity of related neurons in the medulla. Chin J Physiol $\mathbf{5 2}$ (5 Suppl):358-364.

Xie Z, McMillan K, Pike CM, Cahill AL, Herring BE, Wang Q, and Fox AP (2013) Interaction of anesthetics with neurotransmitter release machinery proteins. $J$ Neurophysiol 109:758-767.

Yang CY, Luk HN, Chen SY, Wu WC, and Chai CY (1997) Propofol inhibits medullary pressor mechanisms in cats. Can J Anaesth 44 (7):775-781.

Yang CY, Tan PC, Wu WC, Hsu JC, See LC, and Chai CY (2007) Inhibitory effects of propofol on neuron firing activities in the rostral ventrolateral medulla. Chin $J$ Physiol 50:251-257.

Yang L, Liu H, Sun HY, and Li GR (2015) Intravenous anesthetic propofol inhibits multiple human cardiac potassium channels. Anesthesiology 122:571-584.

Yang YC, Meng QT, Pan X, Xia ZY, and Chen XD (2014) Dexmedetomidine produced analgesic effect via inhibition of HCN currents. Eur J Pharmacol 740:560-564.

Ying SW, Abbas SY, Harrison NL, and Goldstein PA (2006) Propofol block of I(h) contributes to the suppression of neuronal excitability and rhythmic burst firing in thalamocortical neurons. Eur J Neurosci 23:465-480.

Address correspondence to: Xiangdong Chen, Department of Anesthesiology, Institute of Anesthesiology and Critical Care Medicine, Union Hospital, Tongji Medical College, Huazhong University of Science and Technology, Wuhan, Hubei 430022, People's Republic of China. E-mail: xiangdongchen2013@163.com 